\title{
Estrategias cubanas para el empleo femenino en los noventa: un estudio con mujeres profesionales
}

\author{
Marta Núñez Sarmiento \\ Universidad de La Habana. Departamento de Sociología \\ mns@comuh.uh.cu
}

\section{Resumen}

El artículo intenta demostrar cómo Cuba desarrolló en los noventa un proyecto alternativo al neoliberalismo en el terreno del empleo femenino. Para ello la autora resume resultados de varios estudios de caso que emprendió con obreras en empleos tradicionales y no tradicionales femeninos entre 1985 y 1998, para explicar el fenómeno de las mujeres profesionales cubanas, que constitutye el eje de este trabajo. Indaga, entre una muestra de ellas, cuáles fueron las estrategias que elaboraron en los noventa para mantenerse empleadas y reproducir diariamente la vida de sus familias; cómo influyó el hecho de ser profesionales en sus capacidades para tomar decisiones; cuánto han contribuido las mujeres profesionales a cambiar la ideología de género de los hombres cubanos, y qué ha significado ser profesionales en su vida personal.

Palabras clave: mujeres profesionales cubanas, estrategias cubanas de empleo femenino, políticas sociales cubanas de empleo femenino, empleo femenino e ideología de género en Cuba, mujer cubana y toma de decisiones.

\section{Abstract}

The article focuses on how Cuba developed an alternative project to neoliberalism during the 90's to solve problems concerning women's employment. The author summarizes her findings in several case studies she carried out with women employed in traditional and non traditional feminine jobs between 1985 and 1998, in order to explain the development of women professionals, which is the main topic of the present work. Based in a sample of women professionals, she studies which were the strategies they worked out during the 90's to keep their jobs and to daily reproduce the lives of their families; how the fact of being professional women influenced their abilities in decision making; up to what degree they have contributed to change Cuba men's gender ideologies, and what being professionals has meant to their personal lives.

Key words: cuban professional women, cuban strategies for women's employment, cuban social policies for women's employment, women's employment and gender ideology in Cuba, cuban women and decision making. 


\section{Sumario}

La muestra y los métodos

El empleo de las mujeres profesionales y técnicas en los noventa como parte del empleo femenino en Cuba. Políticas sociales que propiciaron esta incorporación y permanencia antes de los noventa: reajustes y nuevas medidas

Estrategias en los noventa para mantenerse ocupadas activamente y para reproducir la vida cotidiana ¿Cuánto ha influido ser profesionales o técnicas en su capacidad para tomar decisiones? ¿'Se sienten capacitadas para ocupar cargos de dirección? ¿Los han ocupado? ¿Desearían hacerlo?
¿Estiman que el fenómeno del empleo femenino en Cuba, y especialmente el de las mujeres profesionales y técnicas, ha modificado las actitudes de los hombres cubanos?

¿Cómo ha influido el hecho de ser mujer profesional y técnica en tus relaciones con tu pareja, con tus padres, con tus hijos y tus colegas de trabajo?

Más sobre la ideología de género de estas profesionales y técnicas Conclusiones

En este artículo contribuyo a explicar por qué considero que Cuba ha enfrentado la crisis de los noventa con un proyecto alternativo al neoliberalismo, en su condición de país subdesarrollado y con un programa socialista que enfatiza eliminar todas las formas de discriminación contra la mujer. De todos los argumentos posibles para esclarecer esta hipótesis, sintetizo los que extraje de un estudio que realicé sobre mujeres profesionales y técnicas en Cuba en los noventa, como parte del empleo femenino cubano. De esta manera intento demostrar cómo no se detuvo ni el fenómeno de la incorporación y permanencia de la mujer en el empleo en Cuba, ni todos los cambios en la ideología de género que ello ha generado en los últimos cuarenta años.

En este trabajo he utilizado los conocimientos acumulados en los estudios de caso con obreras cubanas en empleos tradicionales y no tradicionales femeninos, así como en investigaciones más generales sobre la mujer y el empleo en Cuba, que realicé entre 1985 y $1998^{1}$. Decidí aplicar estos conocimientos

1. Marta NúNÉE SARMiento, La mujer cubana y el empleo en la Revolución cubana, Equipo internacional de investigaciones comparadas sobre la mujer, octubre 1988, Ed. de la Mujer, La Habana; Helen Safa, Marta Núñez, Rosa M. Cartaya, Margarita Flores, Rita Pereira y Raúl Ramos (1987), Estudio de las trabajadoras textiles: balance preliminar en la empresa Ariguanabo (mimeografiado); Marta NúNEZ, Rosa M. CARTAYA, Margarita Flores, Rita PEREIRA y Raúl RAMOS (1987), Informe de la investigación realizada en el combinado textil Celia Sánchez Manduley del 27 de enero al 13 de febrero de 1987 (mimeografiado); Marta NúNEZ, «Las trabajadoras en una fábrica textil. Resultados de una investigación», en «Debate sobre la sociedad cubana», editado por el Seminario Etnológico de la Universidad de Zurich y la Universidad de Berna, 1988; Marta NúŇEZ, Case Study of Cuba: Women and the Economic Crisis, SWEC/1988/CS.2, 9 de septiembre de 1988, United Nations Interregional Seminar on Women and the Economic Crisis, Viena, 3-7 de octubre de 1988; Marta NúNEz, «Estudio de caso de Cuba: dos programas de seguridad y asistencia social dirigidos a la familia y su impacto sobre la mujer", Joint INSTRAW/UNFPA Training Seminar on Women, 
para desentrañar el fenómeno de la alta participación de las mujeres entre los profesionales y técnicos cubanos y su también alta proporción entre las mujeres cubanas ocupadas desde hace más de veinte años. El hecho que esta tendencia no se detuvo en los duros años de crisis y reajustes de los noventa, necesita una explicación por parte de las ciencias sociales cubanas.

El análisis lo hago en dos planos:

- Uno es el plano macro, donde estudio las informaciones estadísticas sobre empleo femenino en Cuba y, en especial, sobre las mujeres profesionales y técnicas, y las políticas sociales que han promovido este movimiento desde la década de 1960. Por ser este aspecto el más conocido, le dedico un espacio menor.

- El segundo plano, al que dedico más atención, lo construí con un estudio de caso que realicé entre fines de 1999 y principios del 2000, en el que entrevisté en profundidad a dieciocho mujeres profesionales y técnicas de la capital del país. En él intento reconstruir aspectos de la ideología de género de estas mujeres en base a los siguientes cuatro temas:

1. ¿Cuáles fueron las estrategias que ellas aplicaron durante los noventa para mantenerse ocupadas activamente y reproducir las vidas de sus familias?

2. ¿Cuánto ha influido ser profesional y técnica en su capacidad para tomar decisiones? ¿Se sienten capacitadas para ocupar cargos de dirección? ¿Los han ocupado? ¿Desean hacerlo?

3. ¿Estiman que el fenómeno del empleo femenino en Cuba, sobre todo en el caso de las mujeres profesionales y técnicas, ha modificado las actitudes de los hombres cubanos?

4. ¿Qué ha significado para las entrevistadas ser profesionales y técnicas en su vida personal? ¿Cómo ha influido su condición laboral en sus relaciones de pareja, en sus relaciones con los padres e hijos y en su entorno laboral?

Population and Development, Santo Domingo, 22-26 de mayo de 1988; Marta NúÑEZ SARMIENTO, Mujeres en empleos no tradicionales, Ed. Ciencias Sociales, La Habana, 1991; Marta NúÑEZ, "La mujer en el periodo especial», revista América Latina, Ed. Ciencia, Academia de Ciencias de Rusia, núm. 12, 1993 (en ruso, Marta NúŃEZ, «Las mujeres de la carreta», diciembre de 1993, Moscú (inédito); Marta NúNEZE, «Proposiciones metodológicas para investigar con enfoque de género", en Jornadas sobre Politicas Sociales en el Marco del Mercosur, Presidencia de la Honorable Cámara de Diputados de la Provincia de Buenos Aires, Centro Integral de la mujer, La Plata, Argentina, 1999; Marta NúÑEz, «La mujer cubana y el empleo: datos y subjetividades (1985-1998)", en Jornadas sobre..., op. cit. en la revista El Economista, año 1, núm.5, La Habana, Cuba, 1998; Marta NúNẼEZ, «Las mujeres de la carreta cinco años después (1992-1997)", ponencia presentada al encuentro La mujer en los umbrales del siglo XXI, Universidad de La Habana, nov. 1997; Marta NúÑEZ, El ajuste económico en los noventa en Cuba y la mujer: realidades y politices para evitar la pobreza, en proceso de publicación; Marta NúNEE, Necesidades y valores, nuevos en la identidad de género en Cuba, en proceso de publicación. 


\section{La muestra y los métodos}

Escogí a las dieciocho profesionales y técnicas para que representaran a distintos grupos de edad entre los veintiocho y sesenta y seis años; que hubieran estudiado sus carreras o las hubieran concluido después de 1959; que hubieran iniciado su vida laboral también durante los años de la Revolución; que ejercieran profesiones diferentes; que fueran de diferentes razas, y tuvieran estados civiles diversos. En cuanto a los hijos, me interesó tener en la muestra a mujeres sin hijos, y a otras que tuvieran uno y más de uno. Como desconozco la distribución estadística de las profesionales cubanas según estas categorías sociodemográficas, no puedo afirmar que ellas sean representativas del resto de sus colegas del país ni de Ciudad de La Habana. Esto, por supuesto, limita las posibilidades de extrapolar sus opiniones y vivencias personales a una población mayor.

Otro elemento que impide esta generalización es que escogí a las dieciocho mujeres porque me conocían. Decidí hacerlo de esta forma porque consideré que así resolvía la cuestión de cómo lograr su confianza para hacer las entrevistas. Y porque estimo que éste es un estudio exploratorio para una investigación más amplia que proyecto para un futuro mediato con profesionales y técnicas en actividades consideradas no tradicionales fuera de Cuba: economistas, abogadas y médicas.

\section{¿Quiénes son estas dieciocho mujeres?}

Dos son mayores de sesenta años; siete están entre los cincuenta y los cincuenta y nueve años; cuatro están entre los cuarenta y los cuarenta y nueve años; cuatro tienen entre treinta y treinta y nueve años, y una tiene veintiocho. Quince son profesionales en medicina, estomatología, economía, arquitectura, cibernética, pedagogía, idiomas. información científico-técnica, sociología, ingeniería civil y piano. Las tres técnicas trabajan en odontología, servicios de lavandería y hay una secretaria ejecutiva con cargo de técnica. Hay nueve blancas, cinco negras y cuatro mulatas. Diez están separadas, divorciadas o son viudas; seis están casadas y hay dos solteras. Catorce tienen hijos (con un promedio de 1,5 hijos por entrevistada, prácticamente idéntica a la tasa global de fecundidad calculada para las cubanas entre 1990 y 1995 , que fue de $1,6^{2}$ y cuatro no tienen hijos. De las que tienen hijos, la edad promedio al tener el primero fue de veintisiete años, que resulta ser nueve años por encima del promedio de las cubanas. El salario promedio de las entrevistadas es de 328 pesos, superior al salario promedio de los trabajadores cubanos en 1999, que fue de 207 pesos. Durante los noventa todas tuvieron que atender a padres y familiares cercanos ancianos. De las dieciocho, once tenían o tienen madres 
trabajadoras, y las madres de las siete restantes eran amas de casa. Entre las madres que trabajaban, solamente una ejerció como profesional y dos como técnicas.

Los métodos que utilicé en este estudio fueron básicamente dos: una entrevista en profundidad y el análisis de documentos.

La entrevista, que fue el procedimiento básico, me sirvió para conocer cómo piensan las seleccionadas lo que significa ser mujer, trabajadora y, específicamente, profesional y técnica en las condiciones concretas en que han vivido. Intenté que reflexionaran sobre la trascendencia de ser mujer en Cuba, sobre todo en los años de la crisis y reajustes de los noventa, y que lo hicieran con ejemplos concretos. Estas conversaciones fueron fluidas y profundas, porque, como anoté antes, todas me conocían, y yo, igual que ellas, soy una profesional que he vivido en Cuba estos años duros.

Los documentos que analicé fueron anuarios estadísticos cubanos, textos de leyes y resoluciones que ilustran la política social cubana con relación a la mujer, materiales elaborados por la Federación de Mujeres Cubanas e investigaciones sobre relaciones de género en Cuba, realizadas por científicas sociales cubanas y colegas de otros países.

\section{El empleo de las mujeres profesionales y técnicas en los noventa como} parte del empleo femenino en Cuba. Políticas sociales que propiciaron esta incorporación y permanencia antes de los noventa: reajustes y nuevas medidas

La proporción de las mujeres en la fuerza de trabajo total del país se incrementó establemente entre $1959(13 \%)$ y $1970(19 \%)^{3}$. Entre 1970 y 1989 el crecimiento mantuvo su estabilidad, pero los incrementos fueron mucho más acentuados que en los once años anteriores: del 19\% en $1970^{4}$ llegó a un 38,7\% en $1989^{5}$. Su número absoluto también subió. De 1989 a 1996 esta tendencia se detuvo: los índices de participación femenina en la fuerza de trabajo oscilaron, y en los años en que se comenzó a salir de la crisis sus valores fueron levemente inferiores al de 1989: 1995 (37,6\%) y 1996 (37,2\%) portamiento se repite en otros cálculos. La participación de la mujer en la ocupación en 1989 fue de 35,5\%, mientras que en 1995 y 1996 fue de 35,1\%.7 Sólo los índices de participación de la mujer en el sector estatal civil mostraron un ligero ascenso: $41,3 \%$ en $1989^{8}$ y $42,3 \%$ en $1997^{9}$.

3. Marta NúNEz SARMiento, La mujer cubana y el empleo en la Revolución cubana, op. cit.

4. Ibídem.

5. Oficina Nacional de Estadísticas, Anuario Estadístico de Cuba 1996, tabla V.11, p. 116.

6. Ibídem.

7. Datos aportados por el Ministerio del Trabajo.

8. «Mujer, economía y desarrollo sostenible», documento de la delegación cubana aportado al Encuentro Internacional de Solidaridad entre Mujeres, La Habana, abril de 1998.

9. Ibídem. 
En los noventa las mujeres se readaptaron a nuevas formas de empleo. Al iniciarse el período especial, la casi totalidad de la fuerza de trabajo del país pertenecía al sector estatal civil. Con la reestructuración económica iniciada alrededor de 1995 que, entre otras cosas, abrió y/o amplió otros sectores no estatales, muchas mujeres cambiaron su orientación ocupacional. Así, en el sector privado, la participación femenina ascendió de un 15,1\% en 1989 a un $22,9 \%$ en $1997^{10}$. En el sector de empresas mixtas y sociedades mercantiles, las mujeres representaron el 34,3\% de todos los trabajadores en $1997^{11}$. La distribución al interior de las mujeres trabajadoras por sectores ocupacionales en 1989 y 1997 confirma esta reorientación laboral femenina. Según datos del Ministerio del Trabajo del total de mujeres ocupadas en 1989, un $89 \%$ trabajaba en el sector estatal civil; en 1997 lo hizo un 81,3\%. Es decir, un 8\% menos. En el sector cooperativo trabajaba en 1989 un $0,8 \%$ de las ocupadas, mientras que en 1997 lo hacía un 5,2\% de ese total. Los índices para el sector privado fueron de un $1,5 \%$ en 1989 y un $2,8 \%$ en 1997 . El sector mixto no existía en 1989; en 1997, del total de mujeres ocupadas, el 2,5\% lo hacía en este nuevo sector. La categoría «otros» se mantuvo estable: 8,7\% en 1989 y 8\% en 1997.

Esta readaptación de las mujeres al redimensionamiento de la economía en la esfera del empleo tiene una lectura positiva en el sentido que las mujeres flexibilizaron su ubicación en la estructura laboral. Pero aún falta por ver si, al hacerlo, se incorporaron a actividades de menor calificación, y si existen ya o se manifestarán en un futuro cercano signos discriminatorios hacia ellas en los sectores privados (especialmente entre los cuenta propistas), en el mixto (indirectamente beneficiado con las divisas) y en el cooperativo.

Desde 1977 la mujer constituye más de la mitad de la fuerza laboral profesional y técnica del país, y la tendencia ha sido a incrementar paulatinamente esta proporción hasta alcanzar el 65,5\% en 1997 . Entre las mujeres ocupadas cubanas, las profesionales y técnicas han sido desde 1978 la categoría ocupacional que agrupa a la mayor proporción de trabajadoras, y la tendencia, desde entonces, ha sido la de incrementar esta proporción.

Ninguna de estas dos tendencias se detuvo en los años de crisis y reajustes de los noventa.

Intentaré explicar por qué este fenómeno se ha comportado de esta manera.

En Cuba ha existido una feminización de la educación, sobre todo en los niveles medio superior y universitario. Cito lo que concluyó el Perfil estadistico de la mujer cubana en el umbral del siglo XXI, donde se evidencia que «[...] cada vez se matriculan más hembras por cada 100 varones en los niveles secundarios y preuniversitarios, llegando a ser en éste último el doble. En ello influyen diversos factores, entre ellos el interés de los varones por matricular preferentemente en cursos de la educación técnica y profesional con el objetivo de acceder más rápidamente al mercado de trabajo y al mismo tiempo adquieren un

10. Datos aportados por el Ministerio del Trabajo.

11. Ibídem. 
nivel de instrucción de hasta 12 grados». «A partir de la década de los ochenta comienza en Cuba un proceso paulatino de feminización de la enseñanza universitaria o superior, ya que alcanza en el curso 1996-97 el 60 por ciento de la matrícula del país en este nivel» ${ }^{12}$. En 1996 las mujeres constituyeron el $65 \%$ de los egresados de los preuniversitarios y de la enseñanza técnica y profesional, y el $58 \%$ de los graduados de los centros de la educación superior ${ }^{13}$.

La fuerza de trabajo femenina, en comparación con la masculina, tiene niveles educacionales más altos. Este comportamiento se mantiene desde 1978. Ese año, el 4,9\% de las mujeres trabajadoras tenía nivel universitario, mientras que entre los hombres trabajadores esta proporción era de un 3,5\%. En 1996 el 16,1\% de las mujeres trabajadoras tenía nivel superior, mientras que entre los hombres trabajadores, éste era de un 10,9\% ${ }^{14}$. En 1978 el 23\% de todas las trabajadoras tenía instrucción media superior en comparación con un 13,3\% de los hombres trabajadores. En 1996 el 44,95\% de todas las trabajadoras tenía instrucción media superior, en comparación con un 32,2\% de los hombres trabajadores ${ }^{15}$.

Las mujeres han ido ocupando plazas en todos los sectores de la economía, tanto en los tradicionalmente femeninos como en los que no lo son. En 1996 el $72 \%$ de las trabajadoras cubanas se concentraron en los sectores de la educación, la industria, la salud pública, el deporte, el turismo y el comercio. El resto se distribuyó en los sectores de la construcción, el agropecuario, el transporte, comunicaciones y otros ${ }^{16}$. En cuanto al total de ocupados en cada sector, el mayor predominio femenino está en educación (61.5\%), salud pública, deporte, turismo $(62,1 \%)$ y finanzas y seguros $(60,7 \%)^{17}$.

Pero también están ocupadas en sectores no tradicionalmente femeninos, en Cuba, por ejemplo, constituyen el 19\% de todos los ocupados en la industria azucarera y el $21 \%$ en la agricultura, entre otros. También han estado presentes en sectores no tradicionales para las mujeres en otros países. Así, en 1994 ellas eran el 55,4\% de los fiscales y el $47 \%$ de los miembros del Tribunal Supremo. Eran, asimismo, el 51\% de los médicos, el 62\% de los médicos de la familia y el $45 \%$ de los científicos ${ }^{18}$.

La explicación más global para este comportamiento del empleo femenino cubano está en el conjunto de políticas sociales dirigidas a eliminar todo tipo de discriminación contra la mujer, del marco legal que se desprende de ellas y de las medidas concretas derivadas de estas políticas. Ellas han estado

12. Oficina Nacional de Estadísticas (ONE). Perfil estadístico..., op. cit., p. 116.

13. "Mujer, economía y desarrollo sostenible», op. cit.

14. Comité Estatal de Estadísticas, Anuario Estadístico de Cuba 1988, tabla IV, 16, p. 202.

15. Ibídem.

16. ONE, Perfil estadístico..., op. cit., p. 141.

17. Ibídem.

18. "La mujer cubana en cifras», documento de Cuba aportado a la Conferencia de Beijing, Ed. de la Mujer, La Habana, 1995. 
funcionando desde los años sesenta, y han estado modificándose constantemente para adecuarse a las realidades y necesidades cambiantes de la sociedad y de las mujeres. He calificado a este proceso del empleo femenino cubano como un "modelo desde arriba y desde abajo». Todas las instituciones del país han participado en diferentes grados en este proceso, pero ha sido la Federación de Mujeres Cubanas la que ha constituido una especie de «conciencia a favor de la mujer» desde su fundación en 1960.

Mencionaré solamente once acciones generadas en los últimos cuarenta años, que han beneficiado a las mujeres trabajadoras y, especialmente, a las profesionales y técnicas. En los noventa ninguna de ellas dejó de operar, y algunas se reajustaron:

1. Ley de maternidad (1974) dentro del Código Laboral, que regula la licencia de maternidad para las trabajadoras. En 1993 se modificó para alargar el período que se les otorga para cuidar al recién nacido.

2. Código de la Familia (1975).

3. Educación gratuita desde el nivel preescolar hasta el postgraduado (desde 1961).

4. Círculos infantiles para niños desde cuarenta y cinco días de nacidos hasta los cinco años. (1961)

5. Comedores escolares en las escuelas primarias para las madres trabajadoras.

6. Becas para los estudiantes que las requieran en todos los niveles de enseñanza.

7. Ubicación laboral asegurada por el Estado para quienes se gradúen de técnicos medios o del nivel universitario.

8. Exigencia a los padres a pagar una pensión alimenticia a sus hijos una vez que se divorcian o se separan de sus parejas.

9. Seguridad social que incluye pagar pensiones y/o jubilaciones. De estas medidas se beneficiaron los padres de las mujeres trabajadoras y las propias trabajadoras ante la muerte de sus cónyuges.

10. Poder disfrutar de un mes de vacaciones una vez al año.

11. Un conjunto de servicios de la salud pública que ha inculcado hábitos en las trabajadoras y sus familias: planificación familiar; pruebas citológicas y de cáncer de mama; vacunación; acceso a los distintos niveles de los servicios de salud, desde el médico de la familia hasta los hospitales e institutos especializados.

Al comenzar la crisis en 1989-1990 las mujeres incorporadas al empleo se habían beneficiado de estas medidas. Como parte de la población cubana, habían vivido décadas de crecimiento económico sostenido, durante las cuales todos, y en especial las mujeres, habían tenido acceso a una distribución más equitativa del ingreso y a niveles decorosos del desarrollo humano. Al comenzar la crisis, por tanto, las reservas humanas, en cuanto a calidad de vida, eran superiores que las de cualquier país del Tercer Mundo. 
Expongo tres argumentos que explican por qué la mujer cubana se mantuvo empleada en estos años de crisis y reajustes:

- Entre las asalariadas cubanas alrededor de una tercera parte son jefas de hogar. Esta mujeres son la única fuente de ingreso de sus hogares, o son las aportadoras más fuertes. Agrego a esta proporción a las mujeres que llevan a sus nuevas uniones maritales a sus hijos de matrimonios anteriores. Estas trabajadoras suelen, por lo general, responsabilizarse de la manutención de sus hijos.

- Como dije antes, las mujeres son en la actualidad las dos terceras partes de los profesionales y técnicos cubanos. En un país como Cuba, cuya estrategia de desarrollo se basa en promover actividades económicas que requieren de alta tecnología y eficiencia, la fuerza laboral altamente calificada es imprescindible. Y, en ella, las mujeres son la mayoría.

- En tanto las asalariadas cubanas se incrementaron sustancialmente en la fuerza laboral total en los últimos veintiocho años (a partir de 1970), entonces puede inducirse que ya hay una considerable proporción de trabajadoras, sobre todo entre las más jóvenes, que son asalariadas de segunda generación por la vía materna. El hecho de contar con referentes empíricos de trabajadoras en sus familias es importante para explicar la permanencia.

El marco legal y político que propició la incorporación y permanencia de las cubanas en la fuerza laboral se mantuvo y se adecuó a las características de la crisis y de los reajustes. Menciono algunos ejemplos de las medidas nuevas instauradas en los noventa para proteger el empleo femenino:

- Redistribución gradual y ordenada de la fuerza de trabajo que resulte en exceso debido a los procesos de redimensionamiento y reestructuración empresarial en aras de buscar una mayor eficiencia económica.

- Protección a los trabajadores que no sea posible redistribuir cuando sus centros de trabajo interrumpen su producción. Ellos reciben el equivalente al $60 \%$ de sus salarios. Asimismo, se aplican subsidios a casos como las madres solas, único sostén de sus hogares, a las discapacitadas mientras no tienen ocupación, a las mujeres en período de gestación.

- Incorporación al trabajo socialmente útil de los segmentos más vulnerables de la población femenina (discapacitadas y madres solas, entre otras).

- Continuar asegurando la incorporación al trabajo de las(os) egresadas(os) de nivel superior y atención a las(os) técnicas(os) de nivel medio.

- Revitalización de las comisiones coordinadoras del empleo femenino, integradas por la Federación de Mujeres Cubanas, la Central de Trabajadores de Cuba y el Ministerio del Trabajo.

- Ampliación de las opciones de empleo en el sector cooperativo (unidades básicas de producción cooperativa y cooperativas de producción agropecuarias) y en el sector privado, particularmente con la consolidación y el desarrollo del trabajo por cuenta propia, así como de entregar tierras ociosas en usufructo a unidades familiares. 
En 1997 el Consejo de Estado aprobó el Plan de Acción Nacional de Seguimiento a la Conferencia de Beijing, que es un documento legal que recoge todas las recomendaciones aprobadas en la Conferencia Mundial de las Naciones Unidas sobre la Mujer, celebrada en la capital china en 1995. Este documento resume la voluntad política del Estado cubano y pone en vigor noventa artículos de un programa para seguir propiciando el progreso de las mujeres cubanas, que son de obligatorio cumplimiento para todas las instituciones estatales cubanas. Se controlaron en un seminario celebrado en 1999 por la Federación de Mujeres Cubanas, y al que asistieron representantes de los organismos estatales.

Las mujeres profesionales y técnicas padecen desigualdades en su cotidianidad, que las afectan física y psíquicamente, al igual que sucede con todas las trabajadoras cubanas. Mencionaré tres de ellas.

Una encuesta de la Oficina Nacional de Estadísticas de Cuba realizada en 1996 concluyó que las trabajadoras cubanas invertían como promedio algo más de treinta y cuatro horas a la semana al trabajo del hogar, mientras que la participación del hombre era de alrededor de doce horas, y fundamentalmente en labores de apoyo ${ }^{19}$.

Las trabajadoras cubanas, consideradas en su conjunto, perciben salarios que representan entre un 80 y un $85 \%$ de los salarios de los hombres. Esta diferencia no se debe a que en Cuba se discrimine a la mujer salarialmente. La Constitución refrenda salario igual por trabajo igual. De lo que se trata es que los hombres constituyen la mayoría absoluta de los ocupados en los sectores económicos que cuentan con los salarios más altos: la minería y la construcción, por ejemplo. Sobre este cociente hay apreciaciones diversas en los cálculos macrosociales: para 1996 los autores de la «Investigación sobre el desarrollo humano en Cuba 1996» señalan en una nota que «[...] el cociente entre los salarios femenino y masculino debiera ser igual a 1,00 , en lugar de $0,75 »^{20}$. En ese mismo trabajo aparece el cociente entre los salarios femenino y masculino con un valor de $0,75^{21}$.

Las mujeres participan en el $31 \%$ de los cargos dirigentes, muy por debajo de las capacidades de instrucción y experiencia laboral que significa constituir las dos terceras partes de los profesionales y técnicos, y tener niveles de educación comparativamente superiores a los de sus colegas.

Hasta aquí expuse sintéticamente los datos estadísticos sobre el comportamiento del empleo femenino en Cuba, con énfasis en los de las profesionales y técnicas, así como las condiciones políticas y legales que lo propiciaron. Estas consideraciones introducen y explican el objetivo principal de este trabajo:

19. ONE, Perfil..., op. cit., p. 148.

20. Centro de Investigaciones de la Economía Mundial (CiEM), Programa de NaCiOnes Unidas para el DesarRollo (PNUD), Investigación sobre el Desarrollo Humano en Cuba, Editorial Caguayo, La Habana, 1997, p. 108.

21. Se extrae del PNUD, Informe sobre el Desarrollo Humano 1996, Madrid, Ediciones Mundiprensa, 1996. p. 160, cuadro 3. 
aproximarme a cómo las mujeres profesionales se piensan a sí mismas como mujeres que se han transformado en sus acciones y subjetividades, y que han contribuido a cambiar a la sociedad en que viven.

\section{Estrategias en los noventa para mantenerse ocupadas activamente y para reproducir la vida cotidiana}

Pregunté cuáles fueron las estrategias que idearon referidas al empleo, al cuidado de los adultos mayores a su cargo y cuánto cambiaron sus estilos de vida ante las carencias del «período especial».

En materia de empleo, todas se mantuvieron empleadas y asumieron, simultáneamente, otros trabajos que les generaron ingresos adicionales. Dieciséis se mantuvieron trabajando en sus profesiones (quince en el Estado y una pasó a ser free lancer) y dos cambiaron de profesión: una pedagoga decidió trabajar como vendedora en una tienda de artículos que se venden en divisas, y una abogada empezó a trabajar de secretaria en una empresa extranjera.

¿Por qué se mantuvieron empleadas, en su mayoría como profesionales?

Escogí algunas respuestas que ejemplifican la necesidad que sintieron de reafirmar su identidad laboral, que tanto esfuerzo les había costado alcanzar y que las dignificaba en su centro de trabajo, su familia y su barrio, en un momento tan crítico de sus vidas. "Mi profesión era el sentido de mi vida». «El mecanismo de defender mi profesión no se puede argumentar económicamente. Estaba defendiendo el papel que yo me había asignado a mí misma, y que no quise abandonar. Era una fidelidad hacia lo que me hace como ser humano». Para todas las profesionales llegó a ser defender una aspiración de años, un ideal que costó mucho trabajo construir. «Hay dos dimensiones: el salario y la profesión. Ésta última ha sido para mí más importante que el salario. El salario perdió su sentido como estimulante en los noventa. La profesión sí se mantuvo como algo que tenía que resistir en ella y desarrollarme». "No dejar de trabajar como profesional me hizo sentirme plena. Me revestí de una coraza para que en ella rebotaran las angustias del período especial». "Había cultivado mi cerebro, mi forma de vida, mi presencia física durante tantos años, y esto no lo podía perder». "Salía del embotamiento de la casa».

El empleo, además, les aseguraba un salario mensual que, aunque deprimido en su valor real, era una entrada estable y considerablemente superior al promedio salarial cubano.

Argumentaron todas que la crisis tenía que terminar, y las plazas las mantendrían para cuando el dinero recuperara su valor y/o aumentaran sus salarios. Asimismo, si se hubieran alejado de sus profesiones, se habrían descalificado.

¿Cuáles fueron las alternativas de actividades para asegurar un segundo ingreso?

- Alquilar cuartos.

- Vender efectos personales.

- Dar clases particulares. 
- Mecanografiar tesis para quienes se graduaban de la universidad o de la enseñanza tecnológica media superior.

- Alquilar su auto por períodos de tiempo, o hacerlo como taxista (sus familiares o ellas mismas).

- Elaborar alimentos y venderlos a dueños de establecimientos particulares o venderlos ellas directamente.

- Coser.

- Viajar al extranjero y ahorrar las dietas que les asignaban.

- Criar pollos para vender huevos.

Las estrategias para cuidar a los padres y otros familiares ancianos en los noventa coincidieron con un momento en que la población cubana que rebasaba los sesenta y cinco años representaba casi el $10 \%$ de la población ${ }^{22}$. Además, en Cuba, los pocos asilos que existen se destinan a ancianos sin amparo familiar. Y la tradición del país critica a quienes mandan a sus padres ancianos a estas instituciones. Lo aceptado es que convivan con sus hijos y nietos. En las condiciones de Cuba, donde el peso de las tareas domésticas recae sobre las mujeres, son las mujeres mayores de cuarenta y cinco años las encargadas de ocuparse de los adultos mayores en sus familias.

En los noventa éste fue el caso de todas las dieciocho profesionales y técnicas entrevistadas, sin abandonar sus empleos.

$\mathrm{Al}$ iniciarse la crisis en Cuba existían políticas sociales, programas e instituciones que se ocupaban de mantener una calidad de vida digna para los adultos mayores: la seguridad social, los servicios de geriatría en policlínicas y hospitales, los médicos de la familia (uno por cada 120 familias, que residen en el barrio), círculos de abuelos y las llamadas "casas de día» (adonde acuden las personas de la tercera edad de 8 de la mañana a 5 de la tarde), y programas de televisión y radio dirigidos a toda la población para promover comprensión y respeto hacia los ancianos. Si todo esto se hubiera mantenido en los noventa, y se hubieran adecuado a las necesidades reales de las personas de la tercera edad, habría sido un apoyo para la mujer trabajadora en las cohortes de cuarenta y cinco años y más.

Pero la crisis afectó esos planes: el valor real de las pensiones y de las jubilaciones se deprimió; los alimentos y las medicinas escasearon; los círculos de abuelos prácticamente cesaron, y no abrieron nuevas casas de abuelos. El médico de la familia y los servicios de geriatría se mantuvieron, pero con enormes limitaciones materiales.

¿Qué hicieron las entrevistadas? Todas pensaron cómo organizar diferentes alternativas con escasos recursos, o, como lo conceptualiza Ofelia Schutte, emprendieron acciones cognoscitivas para desarrollar una «ética del cuidado» ${ }^{23}$. Todas sufrieron desgastes físicos y psíquicos en este proceso.

22. ONE. Anuario Demográfico de Cuba. 1998, tabla 11, p. 55.

23. Ofelia SCHUTTE, «The Ethics of Care and the Creation of Culture», Tenth Conference of North American and Cuban Philosophers, Havana. junio de 1998. 
Todas las dieciocho entrevistadas se propusieron mantenerse empleadas, porque no podían perder sus ingresos. Ninguna pensó en recluirlos en asilos, pero sí adecuaron las condiciones de sus viviendas a las nuevas necesidades de personas que vivían con ellas, y perdían sus facultades físicas y mentales.

Trece se plantearon involucrar a todos los miembros de sus familias nucleares y extendidas para relevarse en este proceso de atención a los ancianos: hijos, primos, tíos, amigas y amigos de la trabajadora y de los ancianos. Sobre todo solicitaron esta participación con el anciano mientras transcurría la jornada laboral de la mujer profesional y técnica. También pagaron en ocasiones a personas no familiares, cuando sus ingresos se lo permitían.

Dos cambiaron de casa para acercarse a los ancianos, si éstos vivían solos. Llevaron a hijos e hijas de ellas a convivir con ellos para cuidarlos y heredar la vivienda. Lo hicieron porque las distancias entre sus casas y las de sus familiares ancianos eran grandes, y el transporte público casi no existía. Se veían obligadas a caminar o a montar en bicicleta.

Priorizaron los gastos para asegurar la alimentación de los nıños y ancianos, generalmente con ingresos provenientes de actividades económicas alternativas. Ellas se afectaron nutricionalmente.

Los ancianos a su cargo recibieron la atención de los médicos y enfermeras de la familia básicamente, y sólo en situaciones extremas acudían a los hospitales, por el difícil acceso al transporte. Emplearon medicamentos provenientes de donaciones que llegaban a las farmacias, o los que les enviaban familiares y amigos residentes o que trabajaban en el extranjero. Comenzaron a usar productos de la medicina verde.

Como dijo una de las entrevistadas: «Es un logro que muchos viejos sobrevivieran estos años con todo tipo de enfermedades y tan pocos recursos. Las mujeres tuvimos que ver mucho con esto».

Los estilos de vida de las dieciocho mujeres cambiaron de varias maneras.

En cuanto al transporte, y teniendo en consideración que entre 1992 y 1997-98 los llamados "transportes obreros» de prácticamente todos los centros de trabajo cesaron, de las dieciocho entrevistadas cinco montaron en bicicleta, una pudo mantener su auto vinculado a su centro de trabajo, mientras que las doce restantes caminaron, pidieron «botellas» y montaron los «camellos». Dos confesaron que al menos dos o tres días a la semana caminaban hasta doce kilómetros.

Las formas de emplear el tiempo libre se transformaron. Dejaron de salir a comer en restaurantes, porque los de moneda nacional cerraron y los que sirven en dólares son muy caros, y comenzaron a organizar reuniones en casas de amigos. También se quedaron en sus casas a mirar la televisión y comenzaron a pasar más tiempo en sus barrios.

Varias insistieron en que reanudaron las visitas a las amistades y a los familiares: en los primeros años del "período especial» nadie visitaba en los horarios de los almuerzos y comidas, porque la comida alcanzaba con trabajo para quienes vivían en las casas visitadas. Tampoco esperaban que les brindaran la tradicional taza de café, y éstas las sustituyeron por cocimientos de cortezas de 
naranjas, hojas de cítricos, hierbas y flores. Ahora, que las condiciones materiales de vida han mejorado, la taza de café retornó y los cocimientos se quedaron.

Una médica muy observadora dijo: «En el período especial se acabó de perder todo afán de apariencia: la gente se demostraba como era. Como todos carecíamos de todo, fuimos perdiendo vergüenzas de no tener lo que otros tenían».

Trece de las dieciocho entrevistadas empezaron a ahorrar en los bancos, con una asiduidad que antes no hacían. Antes vivían «al día», porque los salarios cubrían sus gastos. Quienes ahorraban, lo hacían para gastarlo todo en las vacaciones o para ampliar sus viviendas. Ahora lo hacen "para prepararse para cualquier enfermedad", de ella (que la aleje de su trabajo) o de familiares (que requieran atenciones adicionales a las habituales).

Infiero que todas pasaron por cuatro momentos en estos años de crisis:

- El primero fue de sorpresa ante la caída del campo socialista y el descenso del nivel de vida personal, que se abalanzó sobre todos en menos de un año, a pesar que la más alta dirección del país había prevenido sobre la inminencia del empeoramiento de las condiciones materiales de vida a inicios de 1990, precisamente en un congreso de la Federación de Mujeres Cubanas.

- El segundo fue un momento de depresión, angustia y aturdimiento, porque los niveles de la vida material continuaron decreciendo en todos los aspectos (alimentación, transporte, combustible doméstico, electricidad, insumos para los centros de trabajo, cierre de los centros de trabajo, medicamentos), en comparación con la elevación en la calidad de la vida y del proceso de una movilidad social ascendente desde los sesenta, promovidos por la Revolución. Era la etapa en que «no se veía la salida del hueco». - En el tercero ocurre una suerte de decisión de salir de la depresión por vías hasta el momento insospechadas. Fue el momento de asumir decisiones personales: cambiar de empleo o asumir uno adicional; venderlo todo; emigrar o quedarse; mudarse de casa, de pueblo, de provincia; divorciarse o mantener su pareja. Todo ello se hizo para cubrir los gastos en alimentos básicos para niños y ancianos, así como ropa y calzado para los niños y jóvenes que crecían. Y después de muchos años de estar acostumbrados a vivir bajo la protección casi total del Estado, fue un momento en que todas aprendieron a redefinir sus proyectos de vida individual con poca ayuda estatal. En este momento se torna cada vez más la mirada hacia la comunidad, hacia el barrio.

- Y una cuarta etapa, en la que se vive hoy día con la experiencia de las tres anteriores, que es la de no volver atrás a las calamidades de los primeros años de la crisis.

Durante todos estos momentos, las profesionales y técnicas entrevistadas se dedicaron mucho a preparar a sus hijos para enfrentar cualquier tipo de vicisitudes. Y lo han hecho insistiendo en que se mantengan estudiando. También se han ocupado de su salud personal, para enmendar las enfermedades que 
fueron provocadas por las carencias alimentarias y las tensiones que vivieron cotidianamente por un período que duró casi siete años.

Quiero reflexionar acerca de las condiciones existentes en Cuba, que permitieron que estas estrategias funcionaran:

- Primera condición. Las políticas sociales, los marcos legales y las medidas derivadas de ambos para incorporar a las mujeres al empleo y para que permanecieran en él no se abolieron. Como se explicó en la primera parte de este trabajo, se trató de ajustarlas y de poner en vigor otras nuevas.

- Segunda condición. Se introdujeron medidas económicas nuevas, para enfrentar las condiciones cambiantes en la economía interna y en las nuevas relaciones económicas externas. Mencionaré sólo siete de ellas ${ }^{24}$. Las mujeres entrevistadas elaboraron sus estrategias en el contexto creado por estas medidas, entre otras.

1. En septiembre de 1995 se estableció la ley núm. 77 de la inversión extranjera, que sustituyó el decreto ley núm. 50 de 1982. Su objetivo es el de promover asociaciones con entidades extranjeras que tengan posibilidad de asegurar mercados para las exportaciones, las tecnologías y los recursos financieros complementarios a la parte cubana. Admite crear empresas mixtas, contratos de asociaciones y empresas de capital totalmente extranjero.

2. En 1992 se autorizaron modelos empresariales autofinanciados en divisas. Son empresas y organismos estatales, que comercializan su producción en moneda libremente convertible, y que pueden disponer parte de sus ingresos para cubrir sus egresos en la misma medida que crean los fondos de estimulación para los trabajadores.

3. Despenalización de la tenencia de divisas en 1993 por el decreto ley 140. Autorizó el envío de remesas, la apertura de las casas de cambio y extendió las tiendas de ventas de artículos en divisas.

4. Expansión de los trabajadores por cuenta propia y autorización de otras formas de empleo desempeñadas en el sector privado en 1993. Autorización del arrendamiento de habitaciones en 1997.

5. Reestructuración de las organizaciones de la administración central del Estado 1994, que por el decreto ley 147 suprimió quince ministerios, institutos y comités estatales.

6. Apertura de los mercados agropecuarios y de los mercados artesanales en 1994.

7. Establecimiento del nuevo sistema empresarial en 1998.

- Tercera condición. La vida en el barrio y en la comunidad ha tornado más relevancia en la cotidianidad de todas las personas. Las entrevistadas reco-

24. Batia LAPIDAS y otros, «Factores de la transformación espacial e impacto de agentes económicos seleccionados en el Consejo Popular Vedado-Malecón», Instituto de Geografía Tropical, Ministerio de Ciencia, Tecnología y Medio Ambiente, La Habana, 1999. 
nocieron que en estos años pasaron más tiempo que antes en estos entornos, porque acercaron sus empleos a sus zonas de residencia; porque han buscado más el apoyo de sus vecinos; porque parte de sus estrategias para buscar un segundo ingreso la han realizado con o a través de sus vecinos; porque se han acostumbrado a acudir al médico de la familia y a su policlínica, en vez de a los hospitales.

- Cuarta condición. Durante las décadas de los sesenta, setenta y ochenta la movilidad social ascendente que ocurrió en todo el territorio nacional, y que no se concentró sólo en la capital del país ni en las capitales provinciales, generó en prácticamente toda la población niveles de instrucción, salud, alimentación, seguridad social más altos que los que prevalecían en los cincuenta, y mucho más equitativos que los existentes en otros países del Tercer Mundo.

Esto constituyó un aspecto positivo, en el sentido en que contribuyó a que las mujeres entrevistadas tuvieran ciertas «reservas» para enfrentar la crisis. Pero tuvo el lado negativo que ellas sintieron mucho más cuanto habían perdido con la caída del nivel de vida que sufrió toda la población.

- Quinta condición. Las acciones y las ideas para enfrentar la discriminación de la mujer no se detuvieron en los noventa. Las mujeres desempeñaron un papel visible e imprescindible para que sobreviviera su familia y la economía del país, y esto, estimo, elevó la autoestima de las mujeres a nivel del país. La crisis, además, hizo más visible tanto las desigualdades aún existentes entre mujeres y hombres, como las potencialidades, fortalezas y capacidades de las mujeres cubanas para salir de la crisis en lo individual, familiar, comunitario y del país. Considero que la mujer ha salido de este proceso más fortalecida, como lo pronosticaron la norteamericana Collette Harris en 1995 y Luisa Campuzano en $1996^{25}$.

- Sexta condición. Las características de la psicología social cubana de no dogmatismo, flexibilidad, capacidad para asimilar cambios y emprenderlos contribuyó a la creatividad de las mujeres entrevistadas.

- Séptima condición. Estas mujeres tuvieron que construir sus estrategias viviendo en una sociedad aún patriarcal en la cual ellas llevan el peso de la doble jornada, son los hombres quienes predominan en los cargos de dirección; y, a pesar que por la ley cada quien recibe su salario según el cargo que ocupe, sin deferencias de sexos, los salarios de las mujeres, considerados en su totalidad, representan alrededor de un $80 \%$ del promedio de los hombres.

25. Collette Harris, «Socialist Societies and the Emancipation of Women: The Case of Cuba», en la revista Socialism and Democracy, vol. 9, núm. 1, primavera de 1995, Nueva York. Luisa CAMPUZANO, «Ser cubanas y no morir en el intento», revista Temas, núm. 5, 1996. 


\section{¿Cuánto ha influido ser profesionales o técnicas en su capacidad para tomar decisiones? ¿Se sienten capacitadas para ocupar cargos de dirección? ¿Los han ocupado? ¿Desearían hacerlo?}

Trabajar como profesionales o técnicas ha requerido que todas hayan adquirido conocimientos y experiencias a través de procesos más o menos largos y complejos. Ello ha contribuido, opinan todas, a que ellas se hayan acostumbrado a asumir decisiones en sus puestos de trabajo, bien en aquéllos en los cuales han permanecido más años como en otros nuevos hacia los que se trasladaron temporal o definitivamente.

Ellas tomaron decisiones cuando «construyeron» sus especialidades. Así lo hizo una que quiso ser una buena pianista acompañante y pedagoga en vez de ser una concertista que no estuviera entre las mejores del país. También lo decidió otra que eligió ser una cibernética en lugar de ser una matemática pura. O la socióloga que dejó atrás ser profesora de filosofía. Éstos son algunos ejemplos que explican como todas tuvieron que estudiar en cursos académicos o hacerlo de manera autodidacta a fin de elevar sus calificaciones y/o reorientar sus especialidades. El hecho es que todas manifestaron que aún continúan estudiando para «no quedarse atrás».

Igualmente, asumieron decisiones quienes reorientaron sus ocupaciones en el periodo especial: de pedagoga a vendedora; de abogada a secretaria; de trabajadora estatal a free lancer.

Explicaron que también deciden cotidianamente en su esfera laboral cuando construyen sus planes de trabajo anuales, mensuales y diarios. Muchas han tenido que aprender a decir "no" a tareas que no caben en sus planes de trabajo o que no les interesan. Aquéllas que aún no han incorporado esta cualidad a sus vidas laborales, se ven obligadas a cargar con actividades que no les interesan.

Nueve de las dieciocho entrevistadas optaron por alguna forma de cambio de actividad laboral durante el "período especial», siempre buscando vías para mejorar sus condiciones de vida.

Todas estiman que ellas asumen decisiones constantemente en cuestiones de sus especialidades, sobre todo en las esferas más cercanas de sus ámbitos laborales. Por ejemplo, lo hacen cuando proponen temas a investigar; cuando introducen cambios en la docencia que explican; cuando seleccionan nuevos recursos materiales para sustituir los deficitarios.

A todas les gusta tomar decisiones y participar en llevarlas a cabo, para comprobar que adoptaron las decisiones adecuadas y para aglutinar a otros que las ejecutarán junto a ellas. Les gusta "dar el ejemplo», aunque no sean jefas.

Toman decisiones cuando distribuyen las tareas. Tres confesaron que les ha costado trabajo aprender a delegar y/o a compartir aspectos de la ejecución de las tareas con otras personas, porque esas personas podrían interpretar que ellas están "zafando el cuerpo». Han cometido errores de centralizar excesivamente las responsabilidades, y han sido criticadas fuertemente por ello. 
Quince dijeron que no desean asumir cargos de dirección. Expongo ocho de las razones que trasmitieron:

1. Porque les gusta ser «sus propias jefas», en el sentido de organizar sus proyectos de trabajo a través de un período largo o de una jornada laboral. Esto no significa que no deseen rendir cuentas a un superior jerárquico, ni que tengan vocación de indisciplinadas. Incluye generar tareas que saben se pueden ejecutar, aunque resulten mucho más complejas que las que originalmente aparecían incluidas en sus planes de trabajo.

2. El valor real del «plus» salarial que recibirían por ocupar un cargo de dirección resulta muy pequeño, por la depresión real actual de los salarios en moneda cubana.

3. Sería un agobio adicional a la doble jornada, que no pueden eludir. A los hombres les resulta más fácil aceptar cargos, porque no tienen responsabilidades en sus casas. "Ellos tienen sus retaguardias cubiertas.»

4. La cultura de dirección en Cuba está diseñada por los hombres y para ellos. No es porque los hombres sean más capaces que las mujeres para dirigir. Por ejemplo, a ellos no les cuesta trabajo convocar a reuniones después de concluida la jornada laboral. O ellos prefieren imponer sus ideas, y no tratan de consensuarlas con las personas que ellos dirigen. Estas expresiones coinciden con las conclusiones a las que ha llegado la colega Lic. Graciela González en su estudio sobre mujeres dirigentes en empresas cubanas ${ }^{26}$.

5. Estas mujeres no quieren fracasar como dirigentes. Les costó mucho trabajo llegar a ser buenas profesionales, y les avergonzaría si llegasen a demoverlas de sus cargos de dirección. Eso no sucede con los hombres cuando fallan en los cargos dirigentes, porque a ellos los cambian para otros cargos diferentes.

6. La gente se metería en sus vidas privadas si llegan a ser dirigentes.

7. Ser dirigente es una labor meramente burocrática. «Max Weber ya lo explicó en el siglo XIX», anotó una de ellas.

8. "Cuando una es dirigente se busca problemas, sobre todo cuando propone soluciones que "otros" estiman que no resuelven nada. Y una sabe que ha dado soluciones inteligentes, aunque sea difícil implementarlas y te busques enemigos.» «Es más fácil demostrar que una tiene la razón al aportar soluciones cuando una está en un puesto de profesional.»

Ser profesionales y técnicas les ha permitido tomar decisiones en sus vidas personales. Por ejemplo, todas las que tienen hijos les compulsan a que estudien, para que en el futuro encuentren buenos trabajos. Esto ha sido más duro para siete de las entrevistadas, quienes han encabezado sus hogares mientras sus hijos estudiaban.

Simultanear la jornada laboral con la doméstica y la política ha creado en estas mujeres habilidades para tomar decisiones a "cada minuto»: desde optar

26. Graciela GONZÁLEZ, Las mujeres en la dirección de las empresas industriales. Un estudio de caso en cuatro empresas de Ciudad de La Habana, tesis para optar por el grado de doctora en Sociología, La Habana, febrero del 2000. 
por qué cocinar hasta organizar el horario de su jornada personal cada día (que incluye lo laboral, lo doméstico, lo político y lo recreacional).

Se sienten más preparadas que sus madres para desarrollar la toma de decisiones, tanto en cuestiones «trascendentales» como en las de "todos los días». Y lo hacen casi automáticamente.

Las reflexiones de las entrevistadas sobre su acceso a los puestos de dirección y sus capacidades para tomar decisiones se corresponden con las habilidades que estimo tienen ya las mujeres profesionales y técnicas cubanas hacia el empoderamiento, así como con las condiciones que se han creado en la sociedad cubana para ello.

En primer lugar, se dice que cuando las mujeres alcanzan el saber que antes le era negado como parte de la estrategia de la subordinación patriarcal, entonces poseen una condición imprescindible para ejercer el poder. Las trabajadoras cubanas han «asaltado» el saber de varias formas:

- Por la feminización de la educación en todos los niveles, sobre todo en el universitario y en el preuniversitario, donde son el 58\% y el 65\%, respectivamente, de los egresados.

- Por su presencia entre los científicos (son el 45\% de ellos) y entre los profesores de los centros de la educación superior (alrededor del 60\%).

- Porque representan las dos terceras partes de los profesionales y técnicos cubanos.

- Porque con relación a los hombres trabajadores, poseen niveles de escolaridad más altos.

Segunda condición. Las profesionales y técnicas se han entrenado para tomar decisiones, que es un requisito del ejercicio del poder. Tienen obligatoriamente que tomar decisiones, consciente o inconscientemente, para organizar sus tareas en la jornada laboral, en la «segunda» jornada y en la de los quehaceres políticos y sociales.

Tercera condición. Las asalariadas cubanas, tomadas en su conjunto e incluyendo a las profesionales y técnicas, han promovido laboralmente porque están presentes en todas las categorías ocupacionales (incluida la de dirigentes); desempeñan actividades complejas; incursionan en todas las esferas de la economía (comprendidos empleos no tradicionalmente femeninos), y tienen niveles educacionales más altos que los de los hombres.

Cuarta condición. A lo largo de los mas de cuarenta años de Revolución, cada vez se han visibilizado más los aspectos de discriminación contra la mujer $y$, junto a esto, la necesidad de luchar contra toda forma de discriminación ${ }^{27}$.

27. Mary García Castro y Sherryl Lutjens, «La política desde el género: la contribución feminista latinoamericana a alternativas al neoliberalismo», ponencia presentada en el Seminario internacional: Mundialización, desarrollo sostenible y alternativas al neoliberalismo en Amériea Latina, La Habana, junio de 1998. 
Quinta condición. Las profesionales entrevistadas reconocen que poseen las habilidades para tomar decisiones, y las ejercen, pero la mayoría no desea ejercer el poder «formal».

\section{¿Estiman que el fenómeno del empleo femenino en Cuba, y especialmente el de las mujeres profesionales y técnicas, ha modificado las actitudes de los hombres cubanos?}

Las entrevistadas respondieron que los hombres cubanos han aprendido a respetar más a las mujeres. Este «respeto» a las mujeres ha sido siempre uno de los valores intrínsecos de la psicología social cubana. Su significado de caballerosidad ha tenido mucho contenido patriarcal, en el sentido que a la mujer se le respeta porque es la «madre», la "esposa», el «ser débil al que hay que cuidar». Cuando las entrevistadas dicen que los hombres «respetan más a las mujeres» están incorporando significados nuevos. Esto es, los hombres respetan más a las mujeres, porque ellas trabajan y ganan sus salarios; porque son más independientes; porque están tan preparadas como los hombres para desempeñar profesiones; porque hay mujeres dirigentes, quienes tienen a hombres subordinados bajo su mando; porque los hombres escuchan y aceptan las opiniones de las mujeres con quienes trabajan; porque hay hombres que aceptan que su pareja gane más que ellos; porque algunos aceptan que sus mujeres lleguen del trabajo a la casa después que ellos; porque ya las mujeres trabajadoras no aceptan que los hombres sean violentos con ellas, y los hombres lo saben.

Podría resumir que las entrevistadas consideran que los hombres cubanos han aprendido a ser un poco menos machistas, y las mujeres también. En este proceso las mujeres han tenido un papel mucho más activo que los hombres. Ha sido, además, una evolución que ha ocurrido, a nivel de toda la sociedad, guiada por una política que persigue que la mujer construya su identidad, reconociendo sus individualidades con relación a los hombres, pero sin que se promueva un enfrentamiento con éstos.

Todo este proceso de las mujeres trabajadoras ha llevado a que los hombres realicen públicamente tareas que antes sólo hacían las mujeres. Por ejemplo, pararse en las colas con jabas en las manos para comprar alimentos. Una entrevistada dijo que hay hombres que compran toallas sanitarias en las farmacias para sus hijas y esposas, y a veces salen con ellas exhibiéndolas por las calles cuando no han podido envolverlas.

La pianista me ayudó a comprender lo que está sucediendo en el mundo de la música respecto a las relaciones de género. Explicó que hay un movimiento para rescatar la calidad en los textos de las canciones de la música popular y en la propia melodía. A los salseros se les ha criticado mucho por la baja calidad artística de sus composiciones, teniendo en cuenta que la mayoría de los músicos en la actualidad son egresados de las escuelas de arte. Y como parte de estas críticas está la forma de degradar la imagen de la mujer. Pienso en estribillos de canciones que todos bailan en Cuba, que discriminan a la mujer 
madura, como «A gallina vieja, que le den candela»; o a otras en que, posiblemente por un despecho amoroso, se grita a la mujer «eres una bruja».

A la vez, hay letras que visibilizan las contradicciones que tienen los propios hombres en sus relaciones con mujeres que se han tornado cada vez más independientes. Por ejemplo, está la canción El negro está cocinando, que relata cómo un hombre, divorciado y que vive solo, se ve obligado a "cocinar», en una encubierta alusión al acto sexual, y tiene que hacerlo para sus vecinas, quienes quieren probar «su sazón».

La entrevistada continuó reflexionando sobre las potencialidades que existen entre los músicos cubanos para solucionar este rasgo discriminador. Expresó que los músicos cubanos tienen habilidades para improvisar, tanto en las letras de las canciones como en la ejecución musical. Lo que habría que hacer, continúa la pianista, es encaminarles a que interpreten letras no sexistas.

Añadió que las mujeres han incursionado con éxito en espacios de la música que antes eran cotos cerrados de los hombres. Se refirió a la explosión de conjuntos musicales femeninos, incluso tocando instrumentos de las religiones afrocubanas que antes sólo podían ejecutar los hombres.

Continué indagando sobre los cambios en los hombres cubanos, esta vez en la relación de pareja. Las entrevistadas estiman que hay muchos hombres que no se han adaptado a que sus mujeres trabajen. Esto causó divorcios en dos de las entrevistadas. Sin embargo, sus ex maridos se unieron o se casaron con mujeres trabajadoras. Opinan que ellos necesitaban el salario de su nueva pareja y que ellas, las primeras esposas, les sirvieron como una especie de «entrenamiento» o "aprendizaje» para aceptar convivir con mujeres trabajadoras.

Todas las entrevistadas opinan que los hombres cubanos han cambiado de una u otra forma bajo la influencia de lo que una de ellas describió como la «revolución de las mujeres», y que los cambios variaron en intensidad según las edades: los más viejos están más predispuestos a los cambios, mientras que los jóvenes los aceptan con más naturalidad. Pero todas coinciden en que «todavía vivimos en una sociedad machista».

Puedo ilustrar esto último con lo que escuché decir a un hombre de unos treinta y tantos años en la calle recientemente: "Yo sé hacer todo lo de una casa. Pero si mi suegro ni friega ni limpia, entonces yo tampoco lo hago, porque él no es más macho que yo». En Cuba esta reacción debe estar muy extendida, porque por la escasez de vivienda, conviven bajo un mismo techo hasta tres generaciones. Mantengo, además, la hipótesis que surgió en la investigación sobre las textileras de Ariguanabo en 1987: los hombres tienden a compartir las tareas del hogar con su pareja, cuando ambos trabajan, y logran crear condiciones de vivir en una familia nuclear, incluso cuando viven dentro de una familia extendida.

De esta rica argumentación de las mujeres de la muestra puedo inferir que los hombres han cambiado en sus quehaceres y pensares con relación a la mujer, y que en ello ha influido el fenómeno de las mujeres trabajadoras. Diferentes formas de discriminación contra la mujer se han hecho visibles para toda la sociedad, aunque no se hayan solucionado ni a nivel macro ni a nivel microsocial. 
Me atrevo a hipotetizar sintéticamente algunos de los valores nuevos en la ideología de género de los hombres cubanos en relación con las trabajadoras:

- La mujer trabajadora es una figura social que llegó al escenario laboral cubano para quedarse, y que los hombres aceptan, con sentimientos paradójicos, como compañeras de trabajo, jefas, esposas e hijas.

- Los hombres cubanos van ejerciendo públicamente funciones que antes eran patrimonio exclusivo de las mujeres en la esfera doméstica. Hay menos burlas, pero éstas no han desaparecido totalmente del escenario de la ideología de género.

- Los hombres reconocen que cuando las mujeres trabajan, dependen menos económicamente de ellos.

- Los hombres desean que sus hijas estudien para que trabajen, si fuera como técnicas o profesionales, mejor.

- Los hombres aceptan que las mujeres los dirijan en los centros de trabajo.

- Los hombres aceptan convivir con mujeres que ganen más que ellos.

- Los hombres saben que las mujeres que trabajan no aceptan ser objetos de violencia doméstica.

- La ideología de género que ha presidido este proceso no implica un enfrentamiento entre hombres y mujeres.

Estos valores se están formando, pero están aquí en el escenario de la ideología cubana de género. Cuentan con el respaldo legal, económico, político e ideológico del proyecto socialista cubano. No hay en Cuba, en mi opinión. una «revolución detenida» (stalled revolution), como es el caso de Estados Unidos, que frene la "revolución de las mujeres», que ha existido desde los sesenta.

Las mujeres han desempeñado funciones importantes en estos cambios, sobre todo aquéllas que han sido capaces de «negociar» las transformaciones en las relaciones intergenéricas en sus centros de trabajo, en sus hogares y en sus barrios, cuando ella es trabajadora, profesional y/o dirigente. El papel de las mujeres profesionales y técnicas en cambiar a los hombres excede a sus maridos. Hay que incluir cuánto han influido en modificar las conductas de sus hijos y de los otros miembros masculinos de sus familias para que sean menos machistas.

\section{¿Cómo ha influido el hecho de ser mujer profesional y técnica en tus relaciones con tu pareja, con tus padres, tus hijos y tus colegas de trabajo?}

\section{Relación de pareja}

Las entrevistadas estiman que ser trabajadora profesional y técnica ha contribuido a que ellas sepan cómo quieren que sea su pareja. Esta toma de conciencia a la hora de seleccionar a su pareja la experimentaron las dieciocho entrevistadas en diferentes estadios de sus vidas, y siempre les ocasionó conflictos. 
Ser profesionales y técnicas demanda tiempo, esfuerzos físicos e intelectuales, que se convierten en obligaciones externas a la dinámica de la pareja, y que pueden dañar la convivencia. Pueden, asimismo, enriquecerla si la mujer y el hombre «negocian» y deciden ambos cómo sortear las dificultades. Pero, sin duda, ser profesional exige mucho, $\mathrm{y}$ «una tiene que decidir qué cosa quitar y a quién». Hay casos en que a la mujer le duele quitar ese algo a los hijos, sobre todo cuando son pequeños, y entonces se lo quita a la pareja o a ella misma. Entonces la relación sentimental sufre desgastes, y la mujer suele ser la más afectada.

Las relaciones de pareja pueden sufrir por la competencia profesional que se establece entre el marido y la mujer, sobre todo cuando ella es la que sobresale. Aunque en la base de estos conflictos está la competitividad femenina, las discusiones explotan por motivos más superficiales pero más visibles. Por ejemplo, según los maridos, porque la mujer regresa tarde del trabajo; está siempre cansada; se arregla más para salir a trabajar que para estar en la casa; no atiende bien a los hijos. En dos de los tres casos en los cuales las entrevistadas confesaron que existió una fuerte competitividad con su pareja, hubo manifestaciones de violencia doméstica contra ellas. Una de ellas decidió divorciarse de su marido por esta razón.

Esta mezcla de competitividad profesional y machismo ha sido el detonante de diferentes tipos de conflictos en las parejas de las entrevistadas. Noté diferencias entre las actitudes de las madres de las mayores y de las más jóvenes. Las primeras aconsejaban a sus hijas «ser comprensivas y mantener sus matrimonios por encima de cualquier cosa». Las madres de las más jóvenes les decían que no aguantaran nada de nadie, porque «habían tenido que estudiar mucho para llegar a ser lo que eran».

Aquellas entrevistadas que pasaron por un divorcio, una separación o la viudez, estar trabajando les permitió «salir del hueco». El trabajo fue un refugio para pasar el «duelo» y para sentirse útiles para sacar adelante a sus hijos y a ellas mismas.

Las entrevistadas que están casadas o que lo han estado alguna vez, expresaron que sus maridos iban desde los que no hacían nada en la casa hasta los que compartían con ellas todo el trabajo doméstico. La mayoría de ellas asumía o asume la mayor parte de las tareas del hogar, como sucede con las mujeres cubanas, sean trabajadoras o no.

\section{Relaciones con los hijos}

Todas las entrevistadas con hijos coinciden en que ser profesionales y técnicas les ha servido para orientarles en sus estudios: les han organizado el tiempo extraescolar para que hagan las tareas; les repasan ellas, sus maridos, vecinas, o pagan a repasadores; mantienen económicamente a sus hijos para que concluyan sus estudios. Les han enfatizado la necesidad que estudien para enfrentarse a la vida laboral; han buscado tiempo para sacarles a pasear y conversar con ellos. Todas las que han convivido con sus madres y/o suegras contaron 
con el apoyo de éstas para cuidar a sus hijos mientras ellas trabajaban o se superaban.

El promedio de edad al tener el primer hijo entre las entrevistadas con hijos es de veintisiete años, como lo expuse al describir la muestra. No pude extraer conclusiones entre este dato y el momento de sus vidas laborales en que esto ocurre, porque hay mucha dispersión. Por ejemplo, dos tuvieron su único hijo antes de ser profesionales; en los casos de otras dos que parieron siendo profesionales, una esperó ocho años después de casarse para tener a su hija y otra esperó cuatro años; otra tuvo el primero de sus dos hijos mientras estudiaba su carrera; dos parieron a sus dos hijos después de ser profesionales, pero una los tuvo en el mismo matrimonio y la otra los tuvo en dos matrimonios diferentes; una de las técnicas comenzó a trabajar después que el menor de sus tres hijos tenía ocho años; otra, que es una madre sola, decidió parir cuando era profesional.

Las entrevistadas con hijos estiman que ellas han sido las máximas responsables de la crianza de sus hijos, una vez que se han quedado sin pareja. Ésta es la ideología que vi en otros estudios de caso con obreras, y que se expresa en la idea "A mi hijo lo crío yo porque yo lo parí, y respondo por él».

Durante el "periodo especial» concentraron sus esfuerzos para mantenerse trabajando y lograr ingresos adicionales para asegurar la alimentación de sus hijos, vestirles y calzarles.

De las cuatro entrevistadas que no tuvieron hijos, sólo una hubiera querido tenerlos: ella es estéril. Las otras decidieron no parir porque los hijos no formaban parte de sus proyectos de vida. Dos explicaron que no querían tener hijos sin padre, porque en Cuba la figura paterna es importante. Y porque el hijo debe ser deseado por la madre y por el padre. Una, que está casada, no quiere tenerlo porque estima que su salud no se lo permite, y porque estima que ella ahora no dispone de condiciones económicas para tenerlo. Su marido tiene hijos de matrimonios anteriores, y ella se siente complacida atendiéndolos.

\section{Relaciones con los padres}

Las respuestas de las entrevistas en este epígrafe las agrupé en tres tipos de reflexiones que explican cómo ellas han percibido el papel de sus padres en los diferentes ciclos por los que ellas han pasado en su vida profesional. Están permeadas por el significado que tiene la familia en la cultura cubana y por la necesidad que han tenido prácticamente todas estas mujeres de vivir bajo un mismo techo con familiares de hasta cuatro generaciones.

Primero. Reconocen que sus padres, abuelos y otros familiares cercanos se esforzaron para que ellas llegaran a ser profesionales y técnicas y ejercieran sus conocimientos en sus empleos. Una resumió de esta manera la intención de su padre con sus tres hijas: «Él nos educó como si fuéramos hombres, para que nos quitáramos a los hombres de encima, cuando los tuviéramos a nuestro 
lado y no nos convenían». El referente de tener una madre trabajadora pesó en diez de las dieciocho entrevistadas. Pero reconocieron la influencia que habían tenido sus padres y otros familiares cercanos como patrones a imitar, en su decisión de convertirse en profesionales.

Segundo. Aprecian la ayuda que sus padres y otros familiares de la generación de ellos les dieron para cuidar a sus hijos, desde las edades preescolares hasta que estudiaban en la universidad. También el papel de las madres y familiares femeninas para llevar a cabo las tareas de la doble jornada. Manifiestan, sin embargo, que esta colaboración resulta paradójica, cuando algunas de estas personas no aceptan que las entrevistadas lleguen tarde a la casa a consecuencia de sus trabajos.

Tercero. Explicaron las estrategias para atender a sus padres y familiares de la tercera edad que viven con ellas o que pertenecen a su familia extendida, aunque vivan en otras casas. Las dieciocho entrevistadas enfrentaron esto durante el "periodo especial», y sus experiencias aparecen en el epígrafe de las estrategias.

Insisto en que las experiencias de las entrevistadas ilustran la hipótesis de la Dra. Ofelia Schutte sobre la «ética del cuidado», cuando explica que las mujeres despliegan inteligencia y no sólo sentimientos cuando atienden a los adultos mayores. En este proceso las entrevistadas han desplegado también ternuras y resquemores hacia los ancianos mayores, porque cuidarlos resulta una obligación para «retribuir» lo que hicieron por ellas, pero que las esclaviza.

\section{Relaciones con los colegas del centro de trabajo}

Todas declararon que tuvieron que demostrar su profesionalidad al comenzar a trabajar, más que los hombres que empezaron a trabajar junto a ellas. Se han acostumbrado tanto a desempeñar bien sus profesiones, que ya no les cuesta tanto esfuerzo ser buenas.

De las dieciocho entrevistadas sólo dos reconocieron que fueron discriminadas, porque los hombres no reconocían sus capacidades en cuanto a los conocimientos de sus profesiones, a la capacidad para tomar decisiones y a sus habilidades para soportar el «periodo especial» y mantenerse trabajando. Ambas declararon en las entrevistas que demostraron su capacidad para esto.

Todas sienten que sus colegas de trabajo las respetan.

En sus trabajos, diecisiete se sienten "realizadas», «se me quitan los dolores y achaques», "me olvido de los problemas de la casa», "converso de cosas interesantes». Todas las diez que pasaron por la separación o muerte de sus parejas se refugiaron en sus trabajos para reparar estas pérdidas.

Hay solamente una entrevistada a quien no le gusta trabajar como docente, aunque sí le agrada la especialidad que imparte. Pero reconoce que a su hija le gusta decir que "su mamá es profesional» y a ella le gusta demostrar que es una mujer culta. Le gusta salir de la casa a trabajar porque la casa «embrutece». 
En sus centros de trabajo estas mujeres se relacionan con todas las personas: las de su mismo nivel, las que tienen una preparación inferior y las dirigentes. Tres dijeron que, en sus centros de trabajo, ellas son una especie de "puente» entre los trabajadores con capacidades más altas y más bajas.

En este punto les pregunté qué opinaban de lo que suele decirse que a las mujeres no les gusta trabajar entre mujeres. Todas me ayudaron a desmitificar esta idea. Infiero que la calidad de los llamados "climas de trabajo» no dependen del sexo de quienes integran los colectivos. Las relaciones entre trabajadores se construyen según la profesionalidad de los integrantes del colectivo, de sus habilidades para las interrelaciones personales, de la capacidad de los dirigentes. En los centros de las dieciocho entrevistadas hay mujeres dirigentes, y no provocan desajustes entre los trabajadores por ser mujeres. Al contrario, sus estilos de dirección consensuales, participativos, abiertos a los cambios tienden a unir a las personas.

Las mujeres, me comentaron dos entrevistadas, son capaces de comprender a las otras mujeres cuando han pasado por experiencias tan vitales como parir, criar a un hijo, atender a enfermos y cuidar a los ancianos.

\section{Más sobre la ideología de género de estas profesionales y técnicas}

Solicité a las entrevistadas que comentaran cuatro expresiones populares referidas a la mujer. Aquí van sus reflexiones.

\section{Nadie se me mete en la cocina}

La reacción inmediata de todas fue que "eso es cosa de mujeres de otra generación». "Ni las amas de casa de ahora piensan así.»

Sólo dos confesaron que les gusta cocinar; el resto lo hace por obligación. Sin embargo, razonan que ellas se han desarrollado en las condiciones cubanas del racionamiento o de las enormes carestías del «período especial». Esto significa que llevan años cocinando con «muy poco», «lo justo», con «lo que hay que luchar, porque lo que dan por la libreta no alcanza». Por lo tanto, ellas y sus madres han tenido que desplegar una enorme creatividad y un sentido de ahoro para alimentar a su familia.

"Alimentar a una familia cubana» significa desayunar, almorzar y comer. Además, a los niños en edades preescolares, de primaria y secundaria se les refuerzan los almuerzos con meriendas. A los adolescentes que están becados en preuniversitarios en el campo también se les suple la dieta de sus escuelas con alimentos adicionales.

Los hombres son incapaces de desplegar estos ahorros y creatividades. Cocinar y fregar les corresponde a las mujeres mayores de los hogares multigeneracionales donde han vivido las entrevistadas y también a ellas mismas. Dejan a los hombres otras actividades que antes ellos no hacían que eran del llamado ámbito privado, y que no requieren pericias ahorrativas: comprar alimentos («aunque muchas veces les dan menos de lo que toca por la libreta de 
racionamiento, y ellos no se dan cuenta»), llevar a los niños a los círculos infantiles y a las escuelas.

Esta es la racionalidad de estas mujeres. porque, incluso las que confesaron que les gusta cocinar, lo que desean es «salir lo más rápido posible de la cocina», "no tener que cocinar por obligación todos los días», o simplemente «regalar la cocina».

Entre las entrevistadas dos disfrutan cocinando, y no tanto fregando; dos pagan a otra persona para que lo haga; en otros dos casos son las madres o las abuelas las que cocinan y friegan; siete comparten estas tareas con otras mujeres de sus casas y sólo dos de las que están casadas comparten la cocina con sus maridos.

Una me dijo: «Al hombre hay que darle participación en la cocina, pero con know-how. Otra piensa que sería bueno ir involucrando al hombre poco a poco en la cocina, para que comparta con la mujer esa responsabilidad diaria y para conversar las cosas del día.

Observé las cocinas de las dieciocho entrevistadas, y comprobé que todas estaban ordenadas y limpias. Es cierto que me esperaban; pero, como dije, conozco a estas mujeres y sé que, con altas y bajas, sus cocinas suelen estar limpias.

Pregunté por qué esta limpieza. Respondieron: «No soporto tener ni la cocina ni la casa sucia.» "Llegar a mi casa y verla sucia me deprime.» "¿Qué pensará la gente? ¿Que aquí viven puercos?». Una me dijo que ella siempre tiene limpio "mi Casco Histórico» (refiriéndose a las obras de reconstrucción de La Habana Vieja), que casi siempre es la sala, para recibir a las visitas no anunciadas.

Me atrevo a hacer una disquisición. Creo que estos hábitos de limpieza de estas entrevistadas son parte de la idiosincrasia cubana. Recuerdo los resultados de una encuesta a analfabetos cubanos realizada en 1960, en la que aparecía que estas personas, de bajos ingresos, gastaban mensualmente en detergente y jabón. En mis investigaciones varios años con obreras, vi en sus ropas y en las casas que visité, al menos en la mayoría, estos hábitos de limpieza.

He aquí un ejemplo de ideología de género contradictoria. Las mujeres profesionales y técnicas no quieren perder tiempo en cocinar y fregar, pero buscan vías para asegurar este aspecto de la reproducción de las vidas cotidianas de sus familias.

\section{Hay que ser primero madre antes que mujer y trabajadora}

Las dieciocho entrevistadas coinciden en que se puede y se debe ser las tres cosas a la vez. "Cada cosa tiene su momento.» "Cuando se logra ser las tres cosas, a los hombres les gusta más.» "El marido la respeta más.»

Hay un refrán cubano muy machista que dice: «La mujer tiene que ser ama de casa en la casa, señora en la calle y prostituta en la cama». Como seguramente se construyó cuando las mujeres no trabajaban, a lo de «señora» en la calle habría que añadir, «y trabajadora para que ingrese dinero». Entonces serían 
los cuatro elementos de la mujer ideal para el hombre cubano, aunque conscientemente no reconozca lo del empleo.

Las entrevistadas consideran que las mentalidades de las mujeres y de los hombres cubanos han cambiado en cuanto a las relaciones de género y al papel de la mujer en la sociedad.

Pero las mujeres han sido las que han tenido que hacer "maravillas», "acrobacias» $\mathrm{y}$ «luchar contra el reloj» para cumplir con las tres funciones de madre, esposa y trabajadora.

Aquí infiero que los hombres son los actores pasivos, que fueron los que dictaron las normas de esta «utopía bien machista de la mujer ideal». Por su parte, las propias mujeres, sobre todo con la dinámica que aportaron a la sociedad al incorporarse al empleo, permanecer en él y ascender en la escala de la profesionalidad, excedieron ese esquema: ellas asumen sus responsabilidades como madres (promoviendo, a la vez, la paternidad responsable); conocen más sobre su sexualidad y la planificación familiar, y, además, desempeñan funciones que requieren conocimientos, responsabilidad, generan ingresos relativamente altos y se incorporan cada vez más visiblemente a la toma de decisiones.

Una de las profesionales me comentó: «Esto de ser madre, esposa, ama de casa y trabajadora es muy difícil en un país subdesarrollado como el nuestro. Pienso que debe ser mucho más fácil para las mujeres en los países desarrollados». Me pregunto, ¿qué pensarían de esto Mary García Castro, Helen Safa, Susan Faludi, Elizabeth Jelin, Judith Astelarra y Ann Ferguson, entre otras científicas sociales que han estudiado a la mujer y el empleo en países desarrollados?

Otra entrevistada resumió muy bien lo que he planteado en otros trabajos sobre el modelo cubano de empleo femenino, generado «desde arriba» $\mathrm{y}$ "desde abajo»: "Las cubanas, y sobre todo las profesionales, no han cambiado tanto porque simplemente dijeron "queremos cambiar". Esto se debió a su esfuerzo personal, pero a que lo hicieron en una revolución que les dio todo el apoyo».

\section{La mujer necesita tener a un hombre a su lado para que la represente}

Todas las entrevistadas expresaron de diversas maneras que esto es falso, porque la mujer se representa por sí misma, al menos en Cuba. «Hay otras sociedades donde quizás esto sea necesario, y en Cuba antes también era así. Pero ahora, nadie se cree esto, y menos entre las profesionales.»

Opinan que la mujer sí necesita la compañía de un hombre para compartir su vida, si él vale la pena, y para no estar sola. Para ellas las palabras marido, pareja significan que tiene que haber "amor», "comprensión», "compenetración" y «respeto».

Una de ellas opinó de esta forma: «Hay ocasiones en que quisiera tener a un hombre a mi lado, sobre todo en lugares públicos, para que sea el hombre el que se enfrente a quien me ofende». "En Cuba las mujeres han tenido que decirle muchas veces a los hombres: si yo fuera un hombre, tú no te hubieras atrevido a decirme eso. Eso debe ser porque el hombre es un símbolo de poder.» 
Hubo otra mujer que reflexionó de la manera siguiente: «Los hombres hacen falta en la casa, por ejemplo, para arreglar las cosas. Pero si la mujer puede pagar para que otra persona lo haga, entonces para eso no necesita un marido». Otra expresó muy vívidamente los aspectos paradójicos de su ideología de género: «He estado un sábado limpiando la casa, lavando y cocinando a la vez, y teniéndome una gran autolástima, porque estoy sola y no tengo un marido que me ayude. Se me acerca el mecánico que me está arreglando el auto, para hacerme una consulta. Yo tomo la decisión que él me pidió, y regreso a mis faenas. Entonces me di cuenta que, si hubiera tenido un marido, él habría estado junto al mecánico, y yo habría estado haciendo todas las tareas domésticas que estaba haciendo en ese momento».

En Cuba hay muchas mujeres que encabezan sus hogares. Entre las trabajadoras son aproximadamente una tercera parte, según los estudios de caso que he consultado. Según la ONE, en 1995 del total de las jefas de hogares, un $47 \%$ trabajaba $^{28}$. En esto ha influido la alta tasa de divorcios y la independencia económica que han alcanzado las mujeres a través del empleo.

Estas mujeres solas (por divorcios. separaciones, porque nunca han tenido relaciones estables con hombres o porque han enviudado) eran un estigma hace unos años, y todavía lo son para la mayoría de los hombres cubanos. Quiero estudiar más profundamente la percepción relacional entre hombres y mujeres sobre la soledad femenina en Cuba, y entre las trabajadoras. Tengo una hipótesis: las mujeres solas se han visto obligadas a reconstruir su estado civil de varias maneras. El ideal entre la mayoría de ellas, pienso, es encontrar una nueva pareja "para compartir». En el caso de las profesionales, casi lo puedo asegurar, ella quisiera tener una pareja, pero su criterio de selectividad es alto. Temen un nuevo fracaso, si lo tuvieron en una unión anterior. $Y$ a medida que pasan los años. a los hombres de su edad les gustan las más jóvenes, y a ellos les empiezan a salir los «achaques de la próstata y la impotencia».

Está ocurriendo, por tanto, una reconstrucción de la figura de la «mujer sola». Quizás por eso la respuesta a la frase que encabeza esta parte fue un categórico "Eso es falso.» Y también vale los deseos que expresaron varias de las entrevistadas de encontrar una nueva pareja, cuando dijeron «tengo las puertas abiertas».

¿No será que los hombres en Cuba necesitan más vivir en compañía que las mujeres, porque no saben vivir solos? ¿No será a ellos a quienes habría que preguntarles si están de acuerdo en la expresión «Necesito una mujer que me haga las cosas, para yo poder representarme a mí mismo»?

La primera reacción de las entrevistadas fue negar enfáticamente que requerían que un hombre las representara, porque ellas se valen por sí solas. Después pasaron a argumentar largamente que no están en contra de tener una pareja, y que desearían tener a un hombre para compartir su vida amorosa «en las buenas y en las malas». Quienes están sin parejas estables, añoran tener una 
estabilidad que valga la pena. De aquí infiero que estas mujeres están pasando por un proceso durante el cual están reconstruyendo su concepción del matrimonio, ya sea legal o no. Están redefiniendo lo que significa ser mujer sola en una sociedad como la cubana, donde aún esta condición se estigmatiza. Se trata de un proceso de elevación de la autoestima femenina, con todos los dolores que conlleva.

\section{Conclusiones}

1. El fenómeno de las mujeres profesionales y técnicas en la fuerza de trabajo cubana, en el sentido que desde hace veintidós años constituyen más de la mitad de los profesionales y técnicos del país, y esta categoría agrupa a la mayoría del total de las ocupadas cubanas, también desde 1978, ha sido parte de la evolución del empleo femenino cubano. Sus explicaciones hay que buscarlas en los cambios operados en toda la sociedad cubana desde 1959, en los planos de la economía, la política y la ideología, siguiendo un programa que aspira a eliminar todo tipo de discriminación, incluida la de género. Ha sido un proceso duro y contradictorio, que, a la vez, ha estado cargado de satisfacciones y que ha transformado la ideología de género de todos los cubanos, y no sólo de las mujeres.

2. Estas tendencias continuaron durante los años de crisis y reajustes de los noventa, sin retrocesos sustanciales. Hay, sin embargo, que mantener la conciencia crítica sobre las políticas relativas a la mujer, que ha estado presente en los últimos cuarenta años. Debe tenerse en cuenta que Cuba está saliendo de un proceso de crisis que ha conmovido a toda la sociedad en un período de diez años, con métodos propios, muchos de los cuales han sido concebidos y aplicados en tiempos breves, y que no tiene paradigmas en las experiencias de los países de Europa del Este después del derrumbe del socialismo. Una de las vías que Cuba ha decidido seguir para salir de la crisis es promover la eficiencia y la alta tecnología en los procesos laborales. En tanto las mujeres son las dos terceras partes de los profesionales y técnicos del país, y las trabajadoras tienen niveles educacionales relativamente más altos que los hombres trabajadores, las estrategias que se adopten para el desarrollo no pueden prescindir de estas mujeres.

3. Las y los científicas y científicos sociales cubanos han estudiado con seriedad y creatividad las relaciones de género en Cuba, con énfasis en las mujeres. Tenemos ahora que comprender científicamente qué ha ocurrido con los hombres cubanos en estos últimos cuarenta años. 